\section{Who cycles more? Determining cycling frequency through a segmentation approach in} Montreal, Canada

\author{
Gabriel Damant-Sirois \\ Research Assistant \\ School of Urban Planning \\ McGill University \\ Suite 400, 815 Sherbrooke St. W. \\ Montréal, Québec, H3A 2K6 \\ Canada \\ Tel.: 514-398-4058 \\ Fax: 514-398-8376 \\ E-mail: gabriel.damant-sirois@mail.mcgill.ca \\ Ahmed M. El-Geneidy \\ Associate Professor \\ School of Urban Planning \\ McGill University \\ Suite 400, 815 Sherbrooke St. W. \\ Montréal, Québec, H3A 2K6 \\ Canada \\ Tel.: 514-398-8741 \\ Fax: 514-398-8376 \\ E-mail: ahmed.elgeneidy@mcgill.ca
}

For citation please use : Damant-Sirois, G. \& El-Geneidy, A. (2015). Who cycles more? Determining cycling frequency through a segmentation approach in Montreal, Canada. Transportation Research Part A: Policy and Practice, 77, 113-125. 
1 ABSTRACT

2 The decision to cycle frequently in an urban setting is a complex process and is affected by a 3 variety of factors. This study analyzed the various factors influencing cycling frequency among

$4 \quad 1,707$ cyclists from Montreal, Canada using an ordinal logistic regression. A segmentation of

5 cyclists is used in a series of ordinal logistic models to better understand the different impacts of 6 variables on the frequency of cycling among each group of cyclists for commute and for

7 utilitarian purposes. Our models show a variation in the impacts of each dependent variable on 8 frequency of cycling across the various segments of cyclists. Mainly making cyclists feel safe 9 not only on bicycle specific infrastructure but also on regular streets, emphasizing the low cost, 10 convenience and improving the opinion on cycling in the population are effective interventions 11 to increase bicycle usage. Also, it was shown that women were less likely to cycle to work than 12 men, but more likely to cycle for other utilitarian trips, pointing at the presence of specific 13 barriers to commuting for woman. Although the findings from this study are specific to 14 Montreal, they can be of interest to transportation planners and engineers working towards 15 increasing cycling frequency in other regions. 


\section{INTRODUCTION}

Policy makers and officials promoting cycling often use health, congestion reduction and environmental benefits as a way to convince people to cycle more. While these benefits make an increase in cycling a logical goal for decision makers, they might not be the most effective argument in a promotional campaign or a good guide for planning interventions aimed at increasing bicycle usage. Focusing on the convenience and flexibility of cycling might be a better strategy to increase cycling for utilitarian purposes (Pucher \& Buehler, 2008). Indeed, Börjesson and Eliasson (2012) found that it is better to present cycling as a mode that can compete with others rather than focusing on environmental and health benefits.

There is a vast amount of literature on cycling usage and frequency determinants, but ambiguity remains and conclusions have been inconsistent for many variables (Heinen, van Wee, \& Maat, 2010). For example, several studies found that men cycle more frequently than women (Dill \& Voros, 2007; Stinson \& Bhat, 2004), while some studies suggest otherwise (de Geus, De Bourdeaudhuij, Jannes, \& Meeusen, 2008; Wardman, Tight, \& Page, 2007). Many other variables did not bring consensus, like age, built environment and income. This study builds on past findings to test the importance of the determinants of cycling frequency. It furthermore uses a novel segmentation approach and adds new variables that have not been tested before in previous research. Population segmentation has been shown to nuance results and to be useful in informing decision makers about interventions (Dill \& McNeil, 2013; Geller, 2006; Kroesen \& Handy, 2013). Indeed, different types of cyclists react differently to different types of infrastructure (Larsen \& El-Geneidy, 2011) or to varying conditions (Bergström \& Magnusson, 2003; Nankervis, 1999). This study uses a sample of 1,707 Montreal cyclists and a segmentation analysis that has been developed in a previous study (Damant-Sirois, Grimsrud, \& El-Geneidy, 2014) to understand the determinants of increasing cycling frequencies among specific types of cyclists for different purposes.

The findings of this research can help transportation planners, engineers and policy makers design and effectively adopt interventions or promotional campaigns that can increase bicycle usage in cities. In the following sections we present the relevant literature on determinants of bicycle usage and frequency, and on cyclists' typologies. This is followed by an explanation of the study context and data used. Later we present the methodology, which is followed by a presentation of the analysis and results. The paper ends with a discussion of the results, conclusions and policy recommendations.

\section{BACKGROUND}

\section{Determinants of cycling}

Determinants of cycling can be grouped into four main categories: individual characteristics (e.g. gender, household size), individual attitudes, social environment (e.g. mode of transportation norms, social perception of cyclists), and built environment.

Individual characteristics: While some studies found that age has no clear impact on cycling (Kitamura, Mokhtarian, \& Laidet, 1997; Wardman et al., 2007), most studies observed a variation in cycling usage with age (Dill \& Voros, 2007; O’Connor \& Brown, 2010). With regard to gender, when drawing a general portrait of the cyclist population, the share of women cycling compared to men has been shown to be smaller. Therefore, sex has been explored as a 
determinant of bicycle usage and their relationship has been shown to be significant (Akar, Fischer, \& Namgung, 2013; Landis, Vattikuti, \& Brannick, 1997; Levinson, Krizek, \& Gillen, 2005) and is often explained by claiming that women are more risk averse than men or that women could still be more involved in household responsibilities (J. Garrard, 2003; Heinen et al., 2010). The structure of a cyclist's household has shown to be significantly correlated with bicycle usage (e.g. number of people in household) (Moudon et al., 2005; Ryley, 2006) as is car ownership (Dill \& Voros, 2007; Kitamura et al., 1997; Parkin, Wardman, \& Page, 2008; Stinson \& Bhat, 2004).

Individual attitudes: Fernández-Heredia et al. (2014) show that attitudes can directly influence the intention of cycling, but also the perception of the benefits and barriers of cycling. Probicycle attitudes and pro-car attitudes have both strong and opposite impacts on cycling frequency and behavior (Dill \& Carr, 2003; Fernández-Heredia et al., 2014; Handy \& Xing, 2010; Heinen, Maat, \& van Wee, 2011; Heinen, Maat, \& van Wee, 2013; Vredin Johansson, Heldt, \& Johansson, 2006). Safety perceptions, which are considered to be one of the most important determinants of cycling (Heinen et al., 2011; Rietveld \& Daniel, 2004; Titze, Stronegger, Janschitz, \& Oja, 2007; Xing, Handy, \& Mokhtarian, 2010) are also impacted by individuals' attitudes (Fernández-Heredia et al., 2014). Having a pro-environment attitude has also been shown to be positively correlated to frequent cycling (Li, Wang, Yang, \& Ragland, 2013; Vredin Johansson et al., 2006). Finally, Fernández-Heredia et al.(2014) show that people who see cycling as a way to exercise are more likely to cycle more often.

Social environment: A review of the literature on cycling determinants showed that many studies have found a significant correlation between cycling frequency and different social environment variables (Willis, Manaugh, \& El-Geneidy). Xing and Handy (2008) found that one's social environment was a stronger determinant of bicycle ownership and usage than the built environment. It has a strong impact on the decision to use a bicycle for recreational purposes (Xing et al., 2010). Titze et al. (2007) and Heinen et al. (2013) found that social and peer support for cycling have a strong and positive impact on the decision to commute by bicycle. A study by de Geus et al. (2008) had a similar conclusion and showed that augmenting social support through a campaign would be an efficient way to increasing cycling frequency.

Built environment: This category has been extensively studied and while earlier research found a strong and positive correlation with bicycle usage (Cervero \& Kockelman, 1997; Dill \& Carr, 2003), results have been nuanced with the introduction of self-selection as a control variable (Handy, Cao, \& Mokhtarian, 2005). Self-selection represents the idea that people who already have the intention of cycling will locate themselves in areas that offers substantial bicycle infrastructure. This gives the impression that this type of infrastructure incentivizes people to cycle more. However, even when controlling for self-selection and individual attitudes, some studies still found some correlation between cycling usage and the built environment (Pinjari, Bhat, \& Hensher, 2009; Xing et al., 2010). Some studies also show that infrastructure has an impact on individuals' perceptions of safety while cycling (Carver, Timperio, Hesketh, \& Crawford, 2010; Fraser \& Lock, 2011). Others have demonstrated that infrastructure influences the behavior of cyclists (Krizek, El-Geneidy, \& Thompson, 2007; Menghini, Carrasco, Schüssler, \& Axhausen, 2010; Tilahun, Levinson, \& Krizek, 2007). Finally, commute distance has been shown to be negatively correlated with commuting frequency (Heinen et al., 2013). 
For this study, we include different variables from each of these four categories, while controlling for self-selection. Due to the importance of safety perceptions on cycling frequency, usage, and behavior (Willis et al.), different safety perception measures are included in our analysis, although they were not tested intensively in previous research. McNeil et al. (2015) studied the comfort perception of four cyclists types on different types of infrastructure. However they found that perceptions of comfort did not matched reality. They hypothesized that it might be due to intersections not being taken into consideration when respondents answered the survey. Furthermore, Ma et al. (2014) found that the perceived environment was significantly correlated to cycling behavior while objective environment had only an indirect impact. This study takes a different approach to understanding perceptions of safety. Instead of studying general cycling safety perception separately from infrastructure usage or proximity, this research incorporates safety perceptions of specific infrastructure at intersections and between intersections and its impact on cycling frequency.

\section{Segmentation of cyclists}

Typologies of cyclists have mostly been used to describe the cyclist population (Jensen, 1999; Larsen \& El-Geneidy, 2011), what affects this population (Bergström \& Magnusson, 2003), how they are perceived (Gatersleben \& Haddad, 2010) or their intention of cycling and their perception of cycling safety (Geller, 2006). Damant-Sirois et al. (2014) developed a multidimensional typology that included the motivations and deterrents to cycle, childhood and adulthood encouragement, and route and infrastructure preferences. Dill and McNeil (2013) used the Portland cyclist' typology developed by Geller' (2006) to inform a set of recommendations. Kroesen and Handy (2013) segmented cyclists into four groups to study the relation between non-work related trips and commutes. The two models, one using a segmented sample and the other not, gave similar results, but the impact and level of statistical significance varied across the groups. This shows it might be useful, if the data indicate the pertinence of doing so, to segment a population in order to better understand the factors affecting the different groups of cyclists and to recommend policies tailored to a target audience.

This study examines the impact of previously suggested determinants of bicycle usage by using the typology developed by Damant-Sirois et al. (2014), both on frequency of commute and utilitarian cycling trips (i.e. shopping, grocery shopping and social activities). This typology is developed using a factor analysis followed by a k-means cluster. A total of thirty-five variables were used in the factor analysis and were combined into seven components: impact of weather and effort, time efficiency, peer and institutional encouragement, cycling identity and enjoyment, presence of bicycle infrastructure on the decision to cycle, and the presence and speed of cars, and the parental encouragement during childhood. Using these seven components, the typology divides the cycling population into four distinct groups:

Dedicated cyclists (24\%) are motivated to cycle because of the speed, predictability and flexibility of cycling. Peer and employers/schools can encourage this group to use their bicycle more. They strongly identify themselves as cyclists and enjoy riding their bicycle. They are less keen on using separated infrastructure than the other groups and are not deterred by adverse weather conditions.

Path-using cyclists (36\%) are not strongly impacted by weather conditions either. They have a strong cyclist identity that motivates them to cycle and enjoy riding a bicycle. The main 
difference they have with dedicated cyclists is that they dislike cycling near cars and prefer infrastructure that separates cycling traffic from automobile traffic. In contrast to dedicated cyclists, they were actively encouraged by their parents to cycle both as a sport or recreational activity as well as to reach various destinations.

Fairweather utilitarians(23\%) are best defined as contextual users, since they choose another mode if they perceive it as more convenient. They are unlikely to cycle in bad weather. As path-using cyclists, they prefer to use bicycle paths and are influenced by peers and institutional encouragement. They distinguish themselves from the other clusters because they do not identify as 'cyclists'.

Leisure cyclists (17\%) prefer to use infrastructure segregated from traffic and prefer not to ride close to parked or driving cars. They cycle because they enjoy cycling and because they identify themselves strongly as cyclists, but not because it is a convenient mode. They are the type of cyclists that cycle mostly as a hobby or as a family activity rather than for transportation.

The variables chosen to define the segments come from the literature on cycling determinants. The results made sense when tested with other variables from the same survey (variables such as commuting frequency or safety perceptions using different infrastructures). Finally, every cyclist (one cycling every day or only once a year) can be represented in this typology and the variables used to segment the cyclists are generalizable to different contexts.

One major advantage of this typology compared to others is that it is based on empirical evidence resulting from a large sample of cyclists. Although, the Portland typology developed by Geller (2006) has more frequently been adopted by others, we do not believe that it is reliable for various reasons. For example, Geller (2006) clearly declares the major point of weakness in his typology by stating that "These numbers, when originally assigned, were not based upon any survey or polling data, or on any study. Rather, they were developed based on the professional experience of one bicycle planner.” Later Dill and McNeil (2013) found several contradictions in Geller's approach to segmentation.

The study by Damant-Sirois et al. (2014) developed recommendations on how to increase the frequency of cycling for each type mainly using descriptive statistics and did not analyze the accuracy of their claims nor the power of impact each policy will have on cycling frequency. The goal of the paper was mainly to generate an accurate segmentation and proof its uniqueness through descriptive statistics. Furthermore, no multivariate analysis and only chi-square tests were run to test the similarities and differences between the groups. One of the goals of the current research is to use this typology in a rigorous setting and test the differences between the groups in a multivariate analysis.

\section{STUDY CONTEXT AND DATA}

\section{Study Context}

This study uses answers from cyclists from Montreal, Canada. Montreal has approximately 1.8 million people living in the city and about 3.8 million in the greater region, making it the second largest city in Canada. With regard to transportation mode share, Montreal has the highest combined share of public transit, walking and bicycling in Canada (Statistics Canada, 2011). In the city of Montreal, $36 \%$ of the population aged between 18 and 74 years old cycle at least once 
a week and 52\% at least once a year (Vélo Québec, 2010). The bicycle mode share for commuting in the region is 1.6\% and 3.2\% in the city (Statistics Canada, 2011). This gap between cycling for commute on a regular basis (3.2\%) and the percentage of people who cycled at least once a year or over the past week (52\% and 36\% respectively) needs to shrink if the Montreal region wishes to increase the number of cyclists on the road. This goal is not limited to Montreal but of interest to other regions as well, which makes this paper of value to other regions.

Data

The data used in this study come from a bilingual (French and English) online survey that was available for a month at the end of spring 2013. Guidelines developed by Dillman et al. (2009) were used to reduce sample bias. Following these recommendations, an extensive advertisement campaign was conducted, which included survey links disseminated through the Transportation Research at McGill (TRAM) group mailing-list and other newsletter groups. In addition, socialmedia, French and English newspaper advertisements and articles, flyer distribution to individuals, bicycle shops, businesses along major bicycle paths and around a major bicycle event were also used. Finally, a major radio show interview was conducted.

The survey was aimed only at cyclists. A cyclist is defined as a person who cycled at least once for any purpose in the past year. The number of respondents was 2,644 with a final sample size of 2,004 with complete records. However, the sample size for this particular study is 1,524 for the models analyzing the commute trips and 1,707 for the models studying other utilitarian trips. This difference comes from the fact that respondents who worked from home were removed from the sample for the commute to work model.

The survey was divided into seven main sections presented in the following order: general information, cycling behavior, cycling history, motivations and habits, infrastructure, route and investment, BIXI (Montreal’s bicycle-sharing system), and personal profile. Respondents were asked to state their behavior, home and job location, motivations and deterrents to cycling, and preferences with different subjects like infrastructure, route and intersection, and their safety perception of specific infrastructure types. Most of the variables used in the models come directly from this survey, but others were obtained indirectly through the analysis of geographic characteristics of home and job location.

\section{METHODOLOGY}

The dependent variables used in the multivariate analysis are ordinal. Therefore, an ordered logit regression model is used to analyze the factors affecting the frequency of cycling. The dependent variables were drawn from the following question for different trip purposes: "When you travel for these purposes, how often do you travel by bicycle (including BIXI)?” The possible answers were: Never, Rarely, Sometimes, Often, Always and Not Applicable. Participants who answered Not Applicable were removed from the study. There are pros and cons for categorizing frequency in this way instead of in a continuous manner, like the number of days per week. One disadvantage of ordinal variable in this context is that it might add subjectivity to the respondents answers. However, in the context of this particular research, this data type was most appropriate to answer our research question. Such likert scale observations are meaningful only in relation to other values on the same scale, not in any true quantitative sense (Bowen \& Shenyang, 2011). In other words the frequency of usage need to be measured only against the values questioned in the 
survey. The main advantage for using the former is that it is better at answering the main question of our research without asking the respondents to answer many similar questions. In this case, the fundamental research question was 'what makes individuals choose to use a bicycle for a trip when they make this trip' rather than 'what makes an individual makes a certain amount of trips'. This way, the question controls for differences in life habits (e.g. number of times a week a person shops) or work status (e.g. part-time or full-time). It allows us to differentiate between someone who cycles only once a month to get to work because he or she only works once a month from someone who cycles twice a week to work, but takes a car the other three times. The goal here is to identify the determinants that make people choose to cycle over another mode. This is in line with cities' objective of shifting people from cars to bicycle for the trips they already do, rather than increasing the number of trips per se.

Two models are developed; one for commute frequency and one for other utilitarian trips. The models are applied to the full sample and to the four different types of cyclists described above. A total of 10 regression models are developed. The variables used were inspired by the literature presented above. The rationale behind the models is similar to the one developed by FernándezHeredia et al. (2014), except that the physical determinants (e.g. individual fitness) factor is replaced by a social environment one as it was shown to be more significant in the literature and that physical determinants was not a strong factor in their study.

Table 1 presents the average and standard deviation for every variable used in the study. A chi-square, reported in the table, is used to test if the differences between the four types of cyclists are significant. It is important to note that the variables used in the models are not used to define the types of cyclists to avoid any violations in the assumptions of the statistical technique used. 
1 Table 1 Variables used in the models

\begin{tabular}{|c|c|c|c|c|c|c|c|c|c|c|}
\hline & \multicolumn{2}{|c|}{ All } & \multicolumn{2}{|c|}{$\begin{array}{c}\text { Path-Using } \\
\text { Cyclists }\end{array}$} & \multicolumn{2}{|c|}{$\begin{array}{l}\text { Leisure } \\
\text { Cyclists }\end{array}$} & \multicolumn{2}{|c|}{$\begin{array}{l}\text { Fairweather } \\
\text { Utilitarians }\end{array}$} & \multicolumn{2}{|c|}{$\begin{array}{c}\text { Dedicated } \\
\text { Cyclists }\end{array}$} \\
\hline & Mean & SD & Mean & SD & Mean & SD & Mean & SD & Mean & SD \\
\hline \multicolumn{11}{|l|}{ Dependent variables } \\
\hline \#Commute frequency ${ }^{\star \star *}$ & 3,91 & 1,25 & 4,25 & 1,11 & 3,23 & 1,4 & 3,47 & 1,23 & 4,27 & 1,03 \\
\hline \#Utilitarian trips frequency ${ }^{\star \star \star}$ & 3,16 & 1,16 & 3,52 & 1,04 & 2,19 & 1,06 & 2,8 & 1 & 3,62 & 1,02 \\
\hline \multicolumn{11}{|l|}{ Built environment } \\
\hline Commute distance (km) & 4,64 & 4,13 & 4,38 & 3,52 & 5,68 & 5,72 & 4,19 & 3,57 & 4,76 & 4,05 \\
\hline Walkscore & 82,26 & 14,03 & 84,2 & 12,31 & 74,66 & 17,47 & 83,26 & 12,9 & 83,8 & 13,03 \\
\hline Density (1000pop/km²) & 11,31 & 7,04 & 12,52 & 8,5 & 8,55 & 5,7 & 11,22 & 5,78 & 11,4 & 5,61 \\
\hline \multicolumn{11}{|l|}{ Social environment } \\
\hline $\begin{array}{c}\text { Getting a car is a normal step to become an } \\
\text { adult*** (\%) }\end{array}$ & 0,38 & 0,49 & 0,37 & 0,48 & 0,5 & 0,5 & 0,35 & 0,48 & 0,34 & 0,48 \\
\hline Car is a symbol of social status (\%) & 0,37 & 0,48 & 0,36 & 0,48 & 0,43 & 0,5 & 0,35 & 0,48 & 0,36 & 0,48 \\
\hline Adult cycle ${ }^{\star \star \star}(\%)$ & 0,68 & 0,46 & 0,72 & 0,45 & 0,52 & 0,5 & 0,71 & 0,45 & 0,72 & 0,45 \\
\hline It is a normal to take public transit* (\%) & 0,63 & 0,48 & 0,63 & 0,48 & 0,56 & 0,5 & 0,66 & 0,47 & 0,66 & 0,48 \\
\hline Children cycle (\%) & 0,48 & 0,5 & 0,48 & 0,5 & 0,51 & 0,5 & 0,46 & 0,5 & 0,47 & 0,5 \\
\hline \multicolumn{11}{|l|}{ Self-Selection control } \\
\hline \#Moved for bike infrastructure ${ }^{\star \star \star}$ & 3,02 & 1,17 & 3,26 & 1,13 & 2,88 & 1,18 & 2,87 & 1,14 & 2,89 & 1,19 \\
\hline \multicolumn{11}{|l|}{ Safety perception on different infrastructure types } \\
\hline \#Painted symbol intersection*** & 2,89 & 1,21 & 2,78 & 1,19 & 2,79 & 1,21 & 2,75 & 1,21 & 3,29 & 1,18 \\
\hline \#Painted symbol between*** & 2,79 & 1,20 & 2,69 & 1,18 & 2,68 & 1,22 & 2,62 & 1,17 & 3,21 & 1,18 \\
\hline \#Painted lane intersection ${ }^{\star \star *}$ & 3,25 & 1,11 & 3,15 & 1,13 & 3,12 & 1,13 & 3,20 & 1,13 & 3,56 & 1,00 \\
\hline 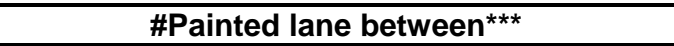 & 3,01 & 1,10 & 2,92 & 1,11 & 2,93 & 1,13 & 2,93 & 1,07 & 3,32 & 1,04 \\
\hline \#Residential intersection*** & 3,61 & 0,98 & 3,55 & 1,00 & 3,51 & 0,93 & 3,47 & 0,96 & 3,91 & 0,94 \\
\hline \#Residential between ${ }^{\star \star *}$ & 3,60 & 0,99 & 3,55 & 1,02 & 3,47 & 0,93 & 3,46 & 1,01 & 3,93 & 0,86 \\
\hline \#Main intersection*** & 2,39 & 1,15 & 2,25 & 1,14 & 2,15 & 1,11 & 2,18 & 1,02 & 3,05 & 1,10 \\
\hline \#Main between*** & 2,05 & 1,00 & 1,88 & 0,92 & 1,91 & 0,97 & 1,88 & 0,87 & 2,65 & 1,04 \\
\hline \#Bi-directional intersection *** & 2,92 & 1,26 & 2,94 & 1,25 & 3,10 & 1,32 & 3,13 & 1,21 & 2,54 & 1,19 \\
\hline \#Bi-directional between*** & 3,60 & 1,20 & 3,70 & 1,17 & 3,57 & 1,24 & 3,74 & 1,14 & 3,32 & 1,22 \\
\hline \multicolumn{11}{|l|}{ Attitudes } \\
\hline \#Environmental motivation*** & 4,2 & 0,89 & 4,45 & 0,78 & 3,93 & 1,06 & 4,02 & 0,82 & 4,16 & 0,9 \\
\hline \#Cost motivation*** & 3,8 & 1,15 & 4,12 & 1,04 & 3,13 & 1,22 & 3,64 & 1,1 & 3,9 & 1,06 \\
\hline \#Health Motivation & 4,22 & 0,86 & 4,35 & 0,83 & 4,42 & 0,75 & 3,99 & 0,83 & 4,07 & 0,92 \\
\hline $\begin{array}{l}\text { \#Cyclists should be more aware of their own } \\
\text { safety }\end{array}$ & 4,04 & 1,02 & 4,08 & 0,99 & 4,08 & 1,02 & 4,04 & 1 & 3,96 & 1,09 \\
\hline $\begin{array}{l}\text { \#Drivers should be more aware of cyclists } \\
\text { safety** }\end{array}$ & 4,6 & 0,74 & 4,68 & 0,62 & 4,54 & 0,81 & 4,5 & 0,84 & 4,61 & 0,73 \\
\hline \multicolumn{11}{|l|}{ Individual characteristics } \\
\hline AGE & 37,34 & 11,54 & 36,06 & 11 & 43,25 & 11,92 & 35,61 & 10,8 & 36,7 & 11,48 \\
\hline Number of people in household & 2,42 & 1,21 & 2,48 & 1,26 & 2,38 & 1,19 & 2,45 & 1,17 & 2,33 & 1,17 \\
\hline Number of cars in household*** & 0,69 & 0,78 & 0,54 & 0,69 & 1,1 & 0,87 & 0,73 & 0,73 & 0,58 & 0,76 \\
\hline \multirow[t]{2}{*}{ 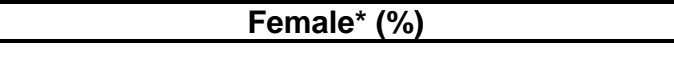 } & 0,4 & 0,49 & 0,41 & 0,49 & 0,31 & 0,46 & 0,42 & 0,49 & 0,41 & 0,49 \\
\hline & \multicolumn{2}{|l|}{$\mathrm{N}=1707$} & \multicolumn{2}{|l|}{$N=658$} & \multicolumn{2}{|l|}{$N=293$} & \multicolumn{2}{|l|}{$N=378$} & \multicolumn{2}{|l|}{$\mathrm{N}=378$} \\
\hline
\end{tabular}

* indicates the level of statistical significant difference across the samples

*Significant at $10 \%,{ }^{*}$ Significant $5 \%$, ** Significant at $1 \%$ 
In Table 1 Variables used in the models commute and utilitarian trip frequency represents the average answer on a 5-likert scale ranging from never to always. The utilitarian trips include grocery shopping, shopping and going to social activities (e.g. restaurant, bar, etc.). The motivation variables come from a question where respondents are asked to rate the importance, on a 5-likert scale, of different sources of motivation to use a bicycle. Health motivation is important for all groups, but is not significantly different between them, while the other two, environmental and cost motivations are.

A series of questions are asked about the importance of different strategies to improve cycling in Montreal. Two of these questions asked respondents to rank the importance, on a 5likert scale, of increasing bicycle safety awareness for cyclists and drivers. The variable moved for bicycle infrastructure comes from a question that asked the importance of different factors in their last home location decision on a 5-likert scale. This variable will help to control for selfselection in the models.

The Walk Score, commute distance and density variables are derived using a Geographic Information System (GIS) and based on respondents' self-reported home and work location. Commute distance is obtained through a network analysis tool in ArcGIS asking for the shortest possible route using a network of streets and bicycle facilities. We can see that the commuting distance is relatively small for each group and that the average Walk Score is quite high. This means that most respondents are living in the central areas of Montreal.

Five variables describing respondents' social environment are obtained through a series of questions where participants are asked to check box if the statement was applicable. These questions were asked following this sentence: "How would you characterize the cycling culture where you live now?" The percentage represents the share of people who considered the statement to be applicable to them. For example, $68 \%$ of the respondents said that it is common for adult to cycle where they live, which is higher than for children at $48 \%$. Standard deviations were relatively high so there is some variance on these variables within group even if they all live in the same city. The last set of variables represents demographic information. There is a statistically significant variation between groups for the number of cars and share of females within each group.

To reduce the number of variables in the statistical models and to account for colinearity, a factor analysis is done to merge similar questions concentrating on safety perceptions and the social environment. The total variance explained for the safety perceptions component is $68 \%$ and $60 \%$ for the social environment one. Table 2 shows the grouping results, the weights of each variable into the component and the name of the new component. 
Table 2 Results from the factor cluster analysis

\begin{tabular}{|c|c|c|}
\hline Component & Variables & Loadings \\
\hline \multirow{3}{*}{$\begin{array}{l}\text { Car-oriented } \\
\text { environment }\end{array}$} & $\begin{array}{c}\text { Getting a car is a } \\
\text { normal step to become } \\
\text { an adult }\end{array}$ & .799 \\
\hline & $\begin{array}{l}\text { Car is a symbol of } \\
\text { social status }\end{array}$ & .743 \\
\hline & \multirow{2}{*}{ Adult cycle } & -.563 \\
\hline \multirow{3}{*}{ Active-oriented } & & .525 \\
\hline & $\begin{array}{l}\text { It is normal to take } \\
\text { public transit }\end{array}$ & .767 \\
\hline & Children cycle & .665 \\
\hline \multirow{4}{*}{$\begin{array}{c}\text { Safety perception } \\
\text { on-street } \\
\text { infrastructure }\end{array}$} & Painted symbol Inter. & .874 \\
\hline & $\begin{array}{l}\text { Painted symbol } \\
\text { Between }\end{array}$ & .873 \\
\hline & $\begin{array}{l}\text { Painted lane } \\
\text { Intersection }\end{array}$ & .694 \\
\hline & Painted lane between & .662 \\
\hline \multirow{4}{*}{$\begin{array}{c}\text { Safety perception } \\
\text { street }\end{array}$} & Residential between & .889 \\
\hline & $\begin{array}{l}\text { Residential } \\
\text { intersection }\end{array}$ & .871 \\
\hline & Main Intersection & .585 \\
\hline & Main between & .528 \\
\hline \multirow{2}{*}{$\begin{array}{c}\text { Safety perception, } \\
\text { separated } \\
\text { infrastructure }\end{array}$} & Bi-directional intersec. & .849 \\
\hline & Bi-directional between & .846 \\
\hline
\end{tabular}

Two distinct social environment components appeared. In the first one, cars have preponderant social importance. In the second, alternative modes, bicycling and transit, are social norms and are well accepted. The variable adult cycle is negatively correlated for the "caroriented” social environment and positively correlated with the other.

The three other components represent the safety perceptions of different groups regarding different infrastructure. Respondents are asked to rate the safety of specific infrastructure between and at intersections. The results gave three distinct groups of infrastructure. The first one is the safety perception of on-street painting, the second is the safety perception of streets without any infrastructure or indication, but with more importance to residential streets than main streets as seen in Table 2, and the last one is the safety perception of infrastructure that separates cyclists from car traffic.

The dependent variables used in the study are the frequency of cycling for commuting and for other utilitarian trips. As expected, by conducting a preliminary analysis and supporting the findings on the types developed previously (Damant-Sirois et al., 2014), some groups were either not represented at all in the never or the always category. Therefore, to meet the proportionality assumption of equivalent distance between each category for an ordered logit regression (tested through a test of parallel lines) some categories were merged. The never category was merged with the rarely category for the commute to work or school. For the 
dedicated cyclists, the new rarely category had to be merged with the sometimes category as there was almost no member of this group in that category. The never category was merged with rarely for both the dedicated cyclists and path-using cyclists, and the always was merged with the often category for the fairweather utilitarians and the leisure cyclists for the utilitarian trips. Also, to test for co-linearity between the variables, a variance inflation factor test is conducted in addition to a regular correlation matrix.

Using the variables presented in Table 1 and the components presented in Table 2, an ordered logit regression is run with the commute and utilitarian trips frequency as dependent variables for the entire sample and for each cyclist's type.

\section{ANALYSIS AND RESULTS}

A total of ten regressions are presented; one for the entire sample and one for each of the four cyclists types for both the commute and utilitarian trips frequency. The results of these regressions give information on two perspectives. First, they test the usefulness for policy and research to segment a population into groups, the adequacy of the typology previously developed and if this typology can be used to inform recommendations made to policy makers on how to increase cycling frequency for different purposes and for different groups. Second, it indicates which factors are correlated with cycling frequency as a mode of transportation which can be used to inform interventions. Table 3 presents the results for the commuting to work frequency regression. The number adjacent to the dependent variable represents the categories of frequency: 2 represents Never and Rarely, 3 Sometimes, 4 Often and 5 Always.

The variables are presented by categories in this order: Built environment, social environment, self-selection (control for the previous two), safety perception, attitudes and individual characteristics. Similar to other research, built environment variables are not significant when controlling for self-selection, except for the commuting distance, which shows that every additional kilometer of commuting distance decreases the chance of being one frequency category higher by about $4 \%$ and by about $8 \%$ for fairweather utilitarians and dedicated cyclists. Even infrastructure distance, representing the home distance to the closest facility, which was initially placed in the models, had to be removed due to its high correlation with the self-selection variable. The commute distance is statistically significant for the entire sample, but has to be nuanced when looking at the different types of cyclists. Interestingly, it is not significant for leisure cyclists even though they have the highest commuting distance and the biggest standard deviation (over 1 time the mean). None of the social environment variables are significant in this model, except for a surprisingly negative correlation between positive social perception of cycling and transit, and cycling commuting frequency for fairweather utilitarians. This could be explained by the fact that the members of this group can easily shift from bicycle to public transit as was explained in Damant-Sirois et al. (2014). 
Table 3 Cycling commuting frequency regression results

\begin{tabular}{|c|c|c|c|c|c|c|c|c|c|c|c|c|c|c|c|}
\hline & \multicolumn{3}{|c|}{ ALL } & \multicolumn{3}{|c|}{ Path-Using Cyclists } & \multicolumn{3}{|c|}{ Leisure Cyclists } & \multicolumn{3}{|c|}{ Fairweather Utilitarians } & \multicolumn{3}{|c|}{ Dedicated Cyclists } \\
\hline & $\begin{array}{c}\text { Odds } \\
\text { ratio }\end{array}$ & $\begin{array}{l}\text { Lower } \\
\text { Bound } \\
\end{array}$ & $\begin{array}{l}\text { Upper } \\
\text { Bound } \\
\end{array}$ & $\begin{array}{c}\text { Odds } \\
\text { ratio }\end{array}$ & $\begin{array}{l}\text { Lower } \\
\text { Bound }\end{array}$ & $\begin{array}{l}\text { Upper } \\
\text { Bound } \\
\end{array}$ & $\begin{array}{c}\text { Odds } \\
\text { ratio }\end{array}$ & $\begin{array}{l}\text { Lower } \\
\text { Bound }\end{array}$ & $\begin{array}{l}\text { Upper } \\
\text { Bound }\end{array}$ & $\begin{array}{c}\text { Odds } \\
\text { ratio }\end{array}$ & $\begin{array}{l}\text { Lower } \\
\text { Bound }\end{array}$ & $\begin{array}{l}\text { Upper } \\
\text { Bound }\end{array}$ & $\begin{array}{l}\text { Odds } \\
\text { ratio } \\
\end{array}$ & $\begin{array}{l}\text { Lower } \\
\text { Bound }\end{array}$ & $\begin{array}{l}\text { Upper } \\
\text { Bound }\end{array}$ \\
\hline [Commu. freq. = 2] & 0.199 & 0.036 & 1.118 & 0.403 & 0.019 & 8.346 & 3.319 & 0.028 & 389.051 & 0.021 & 0.000 & 0.986 & & & \\
\hline [Commu. freq. = 3] & 0.914 & 0.165 & 5.075 & 1.764 & 0.089 & 34.924 & 18.664 & 0.159 & 2194.253 & 0.120 & 0.003 & 5.553 & 0.005 & 0.000 & 0.262 \\
\hline [Commu. freq. = 4] & 8.842 & 1.585 & 49.331 & 19.853 & 0.998 & 395.115 & 405.783 & 3.272 & 50319.728 & 1.334 & 0.029 & 61.121 & 0.061 & 0.001 & 2.890 \\
\hline Commute Distance & $* * * 0.956$ & 0.931 & 0.983 & 0.974 & 0.927 & 1.023 & 0.965 & 0.912 & 1.022 & $* * 0.916$ & 0.856 & 0.981 & $* * \star 0.919$ & 0.865 & 0.976 \\
\hline Walk Score & 1.005 & 0.997 & 1.014 & 1.012 & 0.996 & 1.027 & 0.999 & 0.979 & 1.019 & 0.997 & 0.979 & 1.017 & 0.994 & 0.975 & 1.014 \\
\hline Density (1000/km2) & 1.004 & 0.989 & 1.020 & 0.993 & 0.974 & 1.012 & 1.029 & 0.968 & 1.093 & 1.024 & 0.984 & 1.064 & 0.988 & 0.948 & 1.030 \\
\hline Car-oriented envir. & 1.026 & 0.925 & 1.137 & 0.967 & 0.816 & 1.147 & 1.236 & 0.934 & 1.635 & 0.983 & 0.787 & 1.228 & 1.049 & 0.832 & 1.323 \\
\hline Active-oriented & 0.922 & 0.832 & 1.022 & 1.044 & 0.876 & 1.243 & 0.959 & 0.730 & 1.260 & $* 0.832$ & 0.670 & 1.033 & 0.838 & 0.666 & 1.054 \\
\hline Self-Selection & *1.084 & 0.993 & 1.183 & 1.049 & 0.904 & 1.216 & 1.107 & 0.860 & 1.424 & 1.008 & 0.832 & 1.220 & 0.999 & 0.829 & 1.203 \\
\hline SP on-street & $* \star 1.128$ & 1.021 & 1.247 & 1.037 & 0.872 & 1.233 & 1.210 & 0.905 & 1.618 & 0.863 & 0.684 & 1.090 & 1.142 & 0.917 & 1.422 \\
\hline SP separated & $* * 0.883$ & 0.798 & 0.978 & 0.961 & 0.804 & 1.149 & 0.857 & 0.651 & 1.127 & 1.032 & 0.828 & 1.286 & 0.836 & 0.668 & 1.045 \\
\hline SP Street & $* * * 1.244$ & 1.127 & 1.373 & *1.139 & 0.974 & 1.331 & $* \star 1.411$ & 1.046 & 1.904 & 1.150 & 0.927 & 1.425 & **1.317 & 1.042 & 1.664 \\
\hline Enviro motiva. & 1.075 & 0.943 & 1.227 & 1.111 & 0.874 & 1.411 & 1.037 & 0.751 & 1.432 & 0.889 & 0.669 & 1.180 & 0.959 & 0.716 & 1.284 \\
\hline Cost motiva. & ***1.417 & 1.285 & 1.563 & $* * 1.249$ & 1.051 & 1.487 & $* * * 1.621$ & 1.254 & 2.095 & $* * * 1.325$ & 1.080 & 1.626 & **1.353 & 1.066 & 1.718 \\
\hline Health motiva. & 1.030 & 0.907 & 1.170 & 1.018 & 0.822 & 1.260 & 1.208 & 0.809 & 1.806 & 1.047 & 0.800 & 1.369 & 1.071 & 0.800 & 1.435 \\
\hline Cyclists awareness & ***0.857 & 0.766 & 0.959 & $* * 0.785$ & 0.644 & 0.959 & 1.047 & 0.777 & 1.409 & $* 0.788$ & 0.606 & 1.024 & 0.919 & 0.730 & 1.157 \\
\hline Drivers awareness & ***1.382 & 1.182 & 1.616 & $* * 1.459$ & 1.087 & 1.960 & 1.087 & 0.712 & 1.660 & $* * * 1.599$ & 1.173 & 2.180 & 1.239 & 0.887 & 1.731 \\
\hline Age & ${ }^{* *} 0.925$ & 0.869 & 0.985 & 0.993 & 0.894 & 1.103 & 1.068 & 0.889 & 1.284 & ${ }^{* *} 0.862$ & 0.749 & 0.992 & ***0.820 & 0.712 & 0.945 \\
\hline Age2 & $* * 1.001$ & 1.000 & 1.002 & 1.000 & 0.999 & 1.001 & 0.999 & 0.997 & 1.001 & $* * 1.002$ & 1.000 & 1.004 & $* * 1.002$ & 1.001 & 1.004 \\
\hline HHPeople & **1.097 & 1.005 & 1.196 & 1.102 & 0.956 & 1.272 & 0.923 & 0.707 & 1.204 & 0.995 & 0.820 & 1.206 & 1.122 & 0.917 & 1.372 \\
\hline HHCars & ***0.780 & 0.671 & 0.908 & $* 0.774$ & 0.595 & 1.008 & 0.968 & 0.658 & 1.423 & $* 0.730$ & 0.530 & 1.007 & 0.924 & 0.650 & 1.312 \\
\hline Male & ***1.507 & 1.222 & 1.857 & *1.394 & 0.985 & 1.974 & *1.916 & 1.047 & 3.504 & **1.700 & 1.093 & 2.644 & 1.312 & 0.830 & 2.074 \\
\hline $\begin{array}{l}\text { Sample size } \\
\text { Model fitting sig. }\end{array}$ & & $\begin{array}{l}N=1524 \\
p<0.01\end{array}$ & & & $\begin{array}{l}N=609 \\
p<0.01\end{array}$ & & & $\begin{array}{l}\mathrm{N}=225 \\
\mathrm{p}<0.01\end{array}$ & & & $\begin{array}{l}N=331 \\
p<0.01\end{array}$ & & & $\begin{array}{l}N=359 \\
p<0.01\end{array}$ & \\
\hline
\end{tabular}

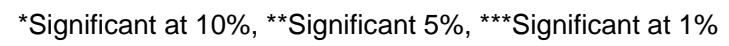


Self-selection is slightly significant $(p<0.10)$ and positively correlated with commuting frequency. However, when segmenting the sample, this variable is not significant for any group and far from it ( $\mathrm{p}=0.430$ for leisure cyclists is the smallest). The safety perception variables are all significant for the entire sample. Safety perception for on-street infrastructure (e.g. painted lanes) and safety perception on streets without infrastructure are positively correlated with the frequency of commuting by bicycle. Interestingly, safety perceptions of facilities that separate cyclists from traffic have a negative correlation with commuting frequency. The safety perception of residential and main streets shows a statistically significant and positive impact on frequency of cycling among three of the four cyclists' types, but not a significant one for the other two safety perception variables.

Two sub-categories of individual attitudes are included in the models: motivations and perceptions of behavior towards other cyclists and drivers. No statistical significance was found between health and environmental motivation and commuting frequency by bicycle. Individuals are aware of these benefits (see Table 1), but what drives them to cycle more is the cost benefit. Indeed, this motivation is strongly significant ( $p<0.01$ or $p<0.05$ depending on types) and has an important impact on frequency. An increase in 1 point on a 5-likert scale of the importance of cost as a motivation to cycle has a probability between $25 \%$ and $62 \%$ depending on types of cyclists or $42 \%$ for the entire sample to be in a higher category of cycling frequency.

Attitudes towards cyclists and drivers are statistically significant for the entire sample, and for path-using cyclists and fairweather utilitarians. Individuals who think that cyclists should be targeted in a safety awareness campaign are less likely to commute by bicycle, while those who think that drivers should be targeted by such policies are more likely to cycle. One way to interpret this variable is that people who think cyclists behave dangerously and should change the way they use the public realm are both less likely to be a frequent cyclist and less likely to want to be seen as one. Therefore, their frequency of usage will likely be lower. On the other hand, people who already cycle more frequently might put the blame on car drivers for conflict between road users.

All of the individual characteristics are significant for the entire sample and follow the expected direction as defined in the literature. Even when controlling for safety perception, males are between $39 \%$ and $91 \%$ more likely to be in a higher category of cycling frequency compared to females depending on cyclist' type. This variable is not significant for dedicated cyclists. In fact, only age is significant for this group. To verify if there are different determinants depending on the purpose of the trips, the same variables, minus commuting distance, are used in the second model that analyzes the factors influencing frequency for utilitarian purposes. Table 4 presents the results of these regression models.

Since most of the results are similar to the ones obtained in the commuting frequency models, the presentation of the results for the utilitarian trips models will concentrate on the differences between the two sets of models. Not surprisingly, the Walk Score variable becomes statistically significant with a positive correlation for this model while the density stays not significant. As Walk Score represents local accessibility (Manaugh \& El-Geneidy, 2011, 2012) to different services, it is normal that an increase of one point in Walk Score increases the odds of being one category higher in utilitarian trips frequency by about $2 \%$ for the whole sample, the path-using cyclists and the fairweather utilitarians. 
There are important differences between the commute and the utilitarian models in the results in terms of individual attitudes. Cost motivation remains strong for each cyclist type, but environmental and health motivations become statistically significant. A one point increase in environmental motivations on a 5-likert scale increase the odds of being in a higher category of frequency of cycling for utilitarian's trips by $29 \%$, 38\% and $40 \%$ for the entire sample, the leisure cyclists and the fairweather utilitarians respectively. The cyclists that have the highest odds ratio for the environmental motivations variable are the ones that cycle the least often. An interesting finding is the strong and negative correlation between health as a motivation to cycle and the frequency of utilitarian trips. It is especially true for fairweather utilitarians that might be deterred from cycling if they see it as an effort and for some dedicated cyclists, while still being defined as cyclists who would cycle in any situation. Indeed, they are defined by the fact they would cycle in any weather condition, that they like the speed of bicycle, they identify themselves as cyclists and enjoy riding, but frequency was not a component used to define the types. Therefore, the dedicated cyclists that are motivated by health might be cycling for sport or recreation activity, but in any context and even on main artery contrary to leisure cyclists who prefer to cycle on bicycle path and in good weather condition. These dedicated cyclists would not necessarily cycle for utilitarian purposes, but are more likely to than the other types. 


\section{Table 4 Cycling for utilitarian trips frequency regression results}

\begin{tabular}{|c|c|c|c|c|c|c|c|c|c|c|c|c|c|c|c|}
\hline & \multicolumn{3}{|c|}{ ALL } & \multicolumn{3}{|c|}{ Path-Using Cyclists } & \multicolumn{3}{|c|}{ Leisure Cyclists } & \multicolumn{3}{|c|}{ Fairweather Utilitarians } & \multicolumn{3}{|c|}{ Dedicated Cyclists } \\
\hline & $\begin{array}{l}\text { Odds } \\
\text { ratio }\end{array}$ & $\begin{array}{l}\text { Lower } \\
\text { Bound }\end{array}$ & $\begin{array}{l}\text { Upper } \\
\text { Bound }\end{array}$ & $\begin{array}{l}\text { Odds } \\
\text { ratio }\end{array}$ & $\begin{array}{l}\text { Lower } \\
\text { Bound }\end{array}$ & $\begin{array}{l}\text { Upper } \\
\text { Bound }\end{array}$ & $\begin{array}{l}\text { Odds } \\
\text { ratio }\end{array}$ & $\begin{array}{l}\text { Lower } \\
\text { Bound }\end{array}$ & $\begin{array}{l}\text { Upper } \\
\text { Bound }\end{array}$ & $\begin{array}{l}\text { Odds } \\
\text { ratio }\end{array}$ & $\begin{array}{l}\text { Lower } \\
\text { Bound }\end{array}$ & $\begin{array}{l}\text { Upper } \\
\text { Bound }\end{array}$ & $\begin{array}{l}\text { Odds } \\
\text { ratio }\end{array}$ & $\begin{array}{l}\text { Lower } \\
\text { Bound }\end{array}$ & $\begin{array}{l}\text { Upper } \\
\text { Bound }\end{array}$ \\
\hline [FreqUt = 1.00] & 0.337 & 0.082 & 1.395 & & & & 2.267 & 0.057 & 90.943 & 0.375 & 0.014 & 10.208 & & & \\
\hline [FreqUt = 2.00] & 1.293 & 0.313 & 5.348 & 0.918 & 0.078 & 10.781 & 10.991 & 0.272 & 444.496 & 1.919 & 0.070 & 52.420 & 0.006 & 0.000 & 0.147 \\
\hline [FreqUt $=3.00]$ & 6.282 & 1.515 & 26.052 & 4.568 & 0.387 & 53.861 & 62.217 & 1.517 & 2551.165 & 14.367 & 0.523 & 394.730 & 0.031 & 0.001 & 0.756 \\
\hline$[$ FreqUt $=4.00]$ & 50.890 & 12.208 & 212.142 & 39.361 & 3.302 & 469.152 & & & & & & & 0.252 & 0.011 & 5.995 \\
\hline Walk Score & $* * * 1.020$ & 1.013 & 1.027 & ***1.019 & 1.006 & 1.032 & 1.010 & 0.993 & 1.026 & **1.019 & 1.003 & 1.036 & 1.007 & 0.990 & 1.023 \\
\hline Density (1000/km2) & 1.003 & 0.990 & 1.017 & 0.996 & 0.978 & 1.013 & 1.009 & 0.964 & 1.055 & 1.012 & 0.976 & 1.050 & 1.001 & 0.965 & 1.038 \\
\hline Self-Selection & **1.093 & 1.013 & 1.180 & 1.064 & 0.935 & 1.211 & 0.952 & 0.777 & 1.167 & *1.177 & 0.994 & 1.394 & 0.978 & 0.832 & 1.150 \\
\hline SP on-street & $* * \star 1.165$ & 1.066 & 1.273 & 0.995 & 0.856 & 1.156 & 1.207 & 0.953 & 1.529 & $* * 1.251$ & 1.010 & 1.550 & 1.070 & 0.880 & 1.303 \\
\hline SP separated & $* * 0.909$ & 0.832 & 0.993 & 1.022 & 0.879 & 1.190 & 0.996 & 0.790 & 1.255 & 0.901 & 0.740 & 1.097 & 0.988 & 0.813 & 1.201 \\
\hline SP Street & ***1.301 & 1.191 & 1.422 & $* * * 1.290$ & 1.121 & 1.485 & **1.365 & 1.065 & 1.750 & 1.114 & 0.918 & 1.353 & 1.013 & 0.822 & 1.248 \\
\hline Car-oriented envir. & 0.931 & 0.850 & 1.019 & 0.920 & 0.793 & 1.067 & 0.855 & 0.679 & 1.077 & 0.955 & 0.778 & 1.171 & 1.009 & 0.824 & 1.236 \\
\hline Active-oriented & 0.927 & 0.847 & 1.016 & 0.947 & 0.814 & 1.102 & 1.001 & 0.798 & 1.256 & 0.893 & 0.734 & 1.087 & 0.983 & 0.804 & 1.204 \\
\hline Enviro motiva. & $* * * 1.289$ & 1.147 & 1.448 & 1.158 & 0.937 & 1.431 & $* * 1.376$ & 1.053 & 1.799 & $* * \star 1.403$ & 1.084 & 1.816 & 1.057 & 0.820 & 1.362 \\
\hline Cost motiva. & $* * * 1.417$ & 1.298 & 1.547 & $* * * 1.307$ & 1.121 & 1.525 & **1.483 & 1.201 & 1.831 & *1.185 & 0.982 & 1.429 & **1.253 & 1.013 & 1.551 \\
\hline Health motiva. & $* * * 0.786$ & 0.701 & 0.881 & 0.859 & 0.711 & 1.036 & 0.887 & 0.628 & 1.254 & *0.785 & 0.613 & 1.005 & **0.737 & 0.571 & 0.951 \\
\hline Cyclists awareness & $* * * 0.849$ & 0.769 & 0.938 & $* * * 0.783$ & 0.663 & 0.924 & **0.758 & 0.578 & 0.996 & 1.013 & 0.808 & 1.271 & 0.955 & 0.782 & 1.166 \\
\hline Drivers awareness & $* * * 1.301$ & 1.134 & 1.494 & ***1.315 & 1.017 & 1.700 & ***1.983 & 1.383 & 2.845 & 1.129 & 0.860 & 1.482 & 1.043 & 0.775 & 1.402 \\
\hline AGE & $* * * 0.919$ & 0.875 & 0.966 & 0.977 & 0.899 & 1.062 & 0.928 & 0.822 & 1.049 & 0.913 & 0.814 & 1.026 & **0.872 & 0.781 & 0.975 \\
\hline Age2 & ***1.001 & 1.000 & 1.001 & 1.000 & 0.999 & 1.001 & 1.001 & 1.000 & 1.002 & 1.001 & 0.999 & 1.002 & **1.001 & 1.000 & 1.003 \\
\hline HHPeople & 0.977 & 0.904 & 1.056 & 0.880 & 0.779 & 0.994 & 0.857 & 0.686 & 1.071 & 1.082 & 0.903 & 1.296 & 0.902 & 0.757 & 1.075 \\
\hline HHCars & $* * * 0.514$ & 0.448 & 0.589 & ${ }^{* * *} 0.596$ & 0.472 & 0.752 & $* * * 0.508$ & 0.357 & 0.723 & $* * * 0.520$ & 0.386 & 0.702 & ***0.554 & 0.409 & 0.751 \\
\hline Male & *0.848 & 0.702 & 1.024 & *0.751 & 0.553 & 1.021 & 0.700 & 0.416 & 1.177 & 1.015 & 0.679 & 1.518 & 1.054 & 0.701 & 1.585 \\
\hline Sample size & $N=1707$ & & & $N=658$ & & & $N=293$ & & & $N=378$ & & & $N=378$ & & \\
\hline Model fitting sig. & $p<0.01$ & & & $p<0.01$ & & & $p<0.01$ & & & $p<0.01$ & & & $p<0.01$ & & \\
\hline
\end{tabular}

*Significant at $10 \%,{ }^{*}$ Significant $5 \%,{ }^{* *}$ Significant at $1 \%$ 
The impact of the number of cars is relatively strong for this kind of trip compared to commuting trips; having one additional car decreases by half the odds of being one category higher in utilitarian trips frequency. It is interesting that contrarily to frequency for commuting trips, males are less likely to cycle for other utilitarian purposes than females. It is only significant $(\mathrm{p}<0.10)$ for the entire sample and the path-using cyclists, but the result is quite contrasting with the other regressions results that gave stronger and opposite direction.

\section{DISCUSSION}

These results confirm that it is important to segment the cyclist population instead of treating them as a homogeneous group. These results also confirm the usability of the typology used in this study. Indeed, while the direction of the relation of the statistically significant variables do not change between types, the significance and size of the odds ratio differ between each type, and between the entire sample and the types. These results are similar to those found by Dill and McNeill (2013) and by Kroesen and Handy (2013) who also used cyclists segmentation in their study. The differences described in this article follow the rationale that was used in the development of this typology (Damant-Sirois et al., 2014). This is an important finding because it shows that, while it is possible to develop sets of tools to increase bicycle usage through general research, a city that knows well its cycling population would develop sets of interventions that would have the biggest impact on the targeted groups.

Many recommendations on interventions aimed at increasing cycling frequency can be extracted from our regression results. As shown in other research (Pucher \& Buehler, 2008), land use policy could have an impact on the frequency of commuting and utilitarian trips by bicycle. Increasing the mix of land uses could reduce the distance between home location and job location and increase the diversity of commerce closer to home. Both of these variables positively impact bicycle usage frequency, except for leisure cyclists. Distance was significant even if the sample was centered in the core of Montreal. This suggests that distance is important even at a small scale. It also indicates that accessibility to services for bicycles should be considered at a relatively small scale because respondents seem to find bicycles convenient and flexible only within a relatively small area. Commuting distance was a significant deterrent even for dedicated cyclists. This results follow what has been found by other researchers (Akar \& Clifton, 2009; Sener, Eluru, \& Bhat, 2009)

While density was found not to be significant in any model, which differs from the initial studies analyzing density (Cervero \& Kockelman, 1997), a certain threshold of density is required to sustain commercial diversity. Therefore, zoning that requires minimum housing density mixed with commercial activities could be a useful tool to reach this objective. This kind of interventions would affect all types of cyclists except leisure cyclists.

An important finding of this study is the varying impact of perceptions of safety along different infrastructure types on cycling frequency. This differentiates this study from previous ones by combining the safety perception on certain infrastructures and its impact on frequency. Previous studies showed that cyclists value cycling facilities and go out of their way to use them (Larsen \& El-Geneidy, 2011), and more so for segregated paths over simple lanes (Broach, Dill, \& Gliebe, 2012). The conclusion found by Broach, Dill and Gliebe (2012), that bicycle lanes offset the effect of adjacent traffic, can be confirmed with the results here. Similar to Ma et al.'s 
(2014) findings, perception of the environment has an impact on cycling behavior. Safety is more important for cyclists than the infrastructure itself. What seems to have the strongest positive impact on cycling frequency is if cyclists feel safe when they are not on a separated facility. This even has an impact on the frequency of dedicated cyclists. This means that what might be really important for increasing bicycle usage is to make people feel safe everywhere in the city, not only when someone reaches a specific types of infrastructure. While this can seem like a huge task compared to deciding which street to build segregated infrastructure on, it also means that broad interventions can have a very important impact. .

Another important finding is the impact of different motivations to cycle and the perceptions towards cyclists on frequency of cycling for utilitarian and commuting trips. The benefits that are put forward in cycling promotional campaigns are mostly concerned with individual health and environmental benefits. As shown in previous studies (Li et al., 2013; Vredin Johansson et al., 2006), environmental impacts of cycling are a motivation that can increase the odds of cycling for utilitarian trips. This is especially for the fairweather utilitarians. However, it does not have a significant impact on commuting. Seeing cycling as a healthy activity is negatively correlated with frequency for utilitarian trips. People who see cycling as an inexpensive mode of transportation are more likely to use it as a mode more frequently. This is true for all segments of the sample. As suggested by Börjesson and Eliasson (2012), promoting cycling by using low cost as an argument might have a stronger positive impact than promoting it using health benefits. The fact that the dedicated cyclists are the ones that are the most motivated by the convenience of cycling points towards other arguments that could be mentioned in a cycling promotional campaign. The speed, flexibility for departure time and for multiple trips, and the predictability of travel time are advantages that should be brought up in such campaign. Also, as indicated by the importance of the social environment variables, campaigns aimed at improving the perception of the population towards cyclists would be an efficient way to increase the usage of bicycling as a mode of transportation.

Other interventions could be developed to promote and enhance the cost benefits of cycling. For example, in Montreal, transit passes are tax deductible, a similar tax incentive could be put in place for cycling. The growing number of cities with bicycle-sharing systems could be a great opportunity to decrease the cost of cycling as it makes it easier than before to plan for ways to include money-incentive interventions in policy package aimed at increasing bicycle usage. Finally, the biggest monetary cost of using a personal bicycle is the purchase of the bicycle; providing safe bicycle parking that prevents bicycle-theft is another strategy that could reduce the cost of cycling.

Finally, even when controlling for safety perceptions, important differences are found between males and females regarding their respective behavior as in other studies (Akar et al., 2013; Jan Garrard, Rose, \& Lo, 2008), except within the dedicated cyclists group. This shows that, while this might be the case, the explanation that women are more risk averse than man is not sufficient. Indeed, they tend to cycle more than men for utilitarian trips. This might be explained by the dress code in work places. Future research should explore the barriers that prevent women from cycling to work. 


\section{CONCLUSION}

This paper studied the relationship between different factors and the frequency of cycling for utilitarian purposes by segmenting a sample of cyclists into four different types using a typology developed in previous research. The points that differentiate this study from previous ones are the segmentation approach and the usage of variables that combined safety perceptions of different infrastructure types. This allowed for a better understanding of the mechanism linking infrastructure, safety and bicycle usage. The results allow for informed decisions to be made regarding interventions aimed at increasing bicycle usage among different groups.

The results confirm the importance of segmenting the cycling population in order to account for the group's heterogeneity. Also, it showed that the typology used in this article results in logically-sound results in both an academic and policy perspective. It nuances the results and indicates which group could be more impacted by different interventions. Depending on the size of each group in a city or region, some interventions would have a stronger impact. It is important to note that some coefficients in the models do fall in between the confidence interval in another model and they are significant in both models, these coefficients represent policies that can be effective to impact more than one group and should have a significant output if they are adopted by the region.

Land use can have an impact on bicycle usage. Using zoning to promote mixed-use development or redevelopment of areas is expected to have a positive impact on bicycle usage. While building a separated bicycle path network could increase usage, it could also give the impression to people that these types of facilities are the only places cyclists can feel safe and should ride, which could lead to a lower modal share of cycling in an area. City planners and engineers should create specific interventions that help cyclists feel safe on residential streets as well. Previous studies found that men cycle more than women because they are more risk averse. The present study shows that when controlling for safety perceptions, women do cycle less than men for commuting purposes, but cycle more for other utilitarian trips. Interventions at work places, like installing a day care, showers, changing rooms, could promote cycling more among females.

The environmental and health benefits of cycling are important. Policy makers must consider these benefits when developing a regional budget. However, these benefits do not seem to directly help in increasing the frequency of cycling. Promoting cycling as a convenient, cheap and safe mode of transportation seems to be a strategy that would more efficiently increase bicycle usage among different groups.

\section{ACKNOWLEDGEMENT}

This research was funded through the National Sciences in Engineering Research Council of Canada (NSERC) Discovery program. We are also grateful to the Coalition Vélo Montréal for input on Montreal bicycle issues and to the Montreal cyclists who filled out the survey and wrote insightful and sometimes extensive comments. Thanks to Michael Grimsrud, Kevin Manaugh, as well as all the Transportation Research at McGill (TRAM) research group members for their support during survey preparation, data collection and cleaning, and their useful analysis insights. Thanks to Alex Legrain, Dea van Lierop and Prof. Richard Shearmur for their feedback on the article. Last, but not least, we would like to thank the two reviewers as their feedback was really helpful through the review process of the manuscript. 


\section{REFERENCES}

Akar, G., \& Clifton, K. J. (2009). Influence of individual perceptions and bicycle infrastructure on decision to bike. Transportation Research Record: Journal of the Transportation Research Board, 2140(1), 165-172.

Akar, G., Fischer, N., \& Namgung, M. (2013). Bicycling choice and gender case study: the Ohio State University. International Journal of Sustainable Transportation, 7(5), 347-365.

Bergström, A., \& Magnusson, R. (2003). Potential of transferring car trips to bicycle during winter. Transportation Research Part A: Policy and Practice, 37(8), 649-666.

Börjesson, M., \& Eliasson, J. (2012). The value of time and external benefits in bicycle appraisal. Transportation Research Part A: Policy and Practice, 46(4), 673-683.

Bowen, N., \& Shenyang, G. (2011). Structurall Equation Modeling: Oxford University Press.

Broach, J., Dill, J., \& Gliebe, J. (2012). Where do cyclists ride? A route choice model developed with revealed preference GPS data. Transportation Research Part A: Policy and Practice, 46(10), 1730-1740.

Carver, A., Timperio, A., Hesketh, K., \& Crawford, D. (2010). Are children and adolescents less active if parents restrict their physical activity and active transport due to perceived risk? Social science \& medicine, 70(11), 1799-1805.

Cervero, R., \& Kockelman, K. (1997). Travel demand and the 3Ds: Density, diversity, and design. Transportation Research Part D: Transport and Environment, 2(3), 199-219. doi: http://dx.doi.org/10.1016/S1361-9209(97)00009-6

Damant-Sirois, G., Grimsrud, M., \& El-Geneidy, A. (2014). What's your type: a multidimensional cyclist typology. Transportation, 41(6), 1153-1169. doi: 10.1007/s11116-014-9523-8

de Geus, B., De Bourdeaudhuij, I., Jannes, C., \& Meeusen, R. (2008). Psychosocial and environmental factors associated with cycling for transport among a working population. Health Education Research, 23(4), 697-708.

Dill, J., \& Carr, T. (2003). Bicycle commuting and facilities in major U.S. cities: If you build them, commuters will use them. Transportation Research Record, 1828, 116-123.

Dill, J., \& McNeil, N. (2013). Four types of cyclists? Examining a typology to better understand bicycling behavior and potential. Paper presented at the Transportation Research Board Annual Meeting, Washington DC.

Dill, J., \& Voros, K. (2007). Factors affecting bicycling demand: initial survey findings from the Portland, Oregon, region. Transportation Research Record: Journal of the Transportation Research Board(2031), 9-17.

Dillman, D., Smyth, J., \& Christian, L. (2009). Internet, mail and mixed-mode surveys: The tailored design method, third edition. Hoboken, NJ: John Wiley and Sons, Inc.

Fernández-Heredia, Á., Monzón, A., \& Jara-Díaz, S. (2014). Understanding cyclists’ perceptions, keys for a successful bicycle promotion. Transportation Research Part A: Policy and Practice, 63, 1-11.

Fraser, S., \& Lock, K. (2011). Cycling for transport and public health: A systematic review of the effect of the environment on cycling. The European Journal of Public Health, 21(6), 738-743. 
Garrard, J. (2003). Healthy revolutions: Promoting cycling among women. Health Promotion Journal of Australia, 14(3), 213-215.

Garrard, J., Rose, G., \& Lo, S. K. (2008). Promoting transportation cycling for women: the role of bicycle infrastructure. Preventive medicine, 46(1), 55-59.

Gatersleben, B., \& Haddad, H. (2010). Who is the typical bicyclist? Transportation Research Part F: Traffic Psychology and Behaviour, 13(1), 41-48.

Geller, R. (2006). Four types of cyclists. Portland, OR: Retrieved from http://www.portlandoregon.gov/transportation/article/264746.

Handy, S., Cao, X., \& Mokhtarian, P. (2005). Correlation or causality between the built environment and travel Behavior? Evidence from Northern California. Transportation Research Part D: Transport and Environment, 10(6), 427-444.

Handy, S., \& Xing, Y. (2010). Factors correlated with bicycle commuting: A study in six small U.S. cities. International Journal of Sustainable Transportation, 5(2), 91-110. doi: $10.1080 / 15568310903514789$

Heinen, E., Maat, K., \& van Wee, B. (2011). The role of attitudes toward characteristics of bicycle commuting on the choice to cycle to work over various distances. Transportation Research Part D: Transport and Environment, 16(2), 102-109.

Heinen, E., Maat, K., \& van Wee, B. (2013). The effect of work-related factors on the bicycle commute mode choice in the Netherlands. Transportation, 40(1), 23-43.

Heinen, E., van Wee, B., \& Maat, K. (2010). Commuting by bicycle: An overview of the literature. Transport reviews, 30(1), 59-96.

Jensen, M. (1999). Passion and hearth in transport: A Sociological analysis on transport behaviour. Transport Policy, 6, 19-33.

Kitamura, R., Mokhtarian, P., \& Laidet, L. (1997). A micro-analysis of land use and travel in five neighborhoods in the San Francisco Bay Area. Transportation, 24(2), 125-158.

Krizek, K., El-Geneidy, A., \& Thompson, K. (2007). A detailed analysis of how an urban trail system affects cyclists' travel. Transportation, 34(5), 611-624.

Kroesen, M., \& Handy, S. (2013). The relation between bicycle commuting and non-work cycling: results from a mobility panel. Transportation, 1-21. doi: 10.1007/s11116-013-9491-4

Landis, B., Vattikuti, V., \& Brannick, M. (1997). Real-time human perceptions: Toward a bicycle level of service. Transportation Research Record(1578), 119-126.

Larsen, J., \& El-Geneidy, A. (2011). A travel behavior analysis of urban cycling facilities in Montreal Canada. Transportation Research Part D: Transport and Environment, 16(2), 172-177.

Levinson, D. M., Krizek, K. J., \& Gillen, D. (2005). The Machine for Access. In D. M. Levinson \& K. J. Krizek (Eds.), Access to Destinations (pp. 1-16): Elsevier

Li, Z., Wang, W., Yang, C., \& Ragland, D. (2013). Bicycle commuting market analysis using attitudinal market segmentation approach. Transportation Research Part A: Policy and Practice, 47, 56-68.

Ma, L., Dill, J., \& Mohr, C. (2014). The objective versus the perceived environment: what matters for bicycling? Transportation, 41(6), 1135-1152. 
Manaugh, K., \& El-Geneidy, A. (2011). Validating walkability indices: How do different households respond to the walkability of their neighbourhood? Transportation research Part D: Transport and Environment, 16(4), 309-315.

Manaugh, K., \& El-Geneidy, A. ( 2012). What makes travel "local": Defining and understanding local travel behavior. The Journal of Transport and Land Use, 5(3), 15-27.

McNeil, N., Monsere, C. M., \& Dill, J. (2015). The Influence of Bike Lane Buffer Types on Perceived Comfort and Safety of Bicyclists and 1 Potential Bicyclists 2. Paper presented at the Transportation Research Board 94th Annual Meeting.

Menghini, G., Carrasco, N., Schüssler, N., \& Axhausen, K. (2010). Route choice of cyclists in Zurich. Transportation Research Part A: Policy and Practice, 44(9), 754-765.

Moudon, A., Lee, C., Cheadle, A., Collier, C., Johnson, D., Schmid, T., \& Weather, R. (2005). Cycling and the built environment, a US perspective. Transportation Research Part D: Transport and Environment, 10(3), 245-261.

Nankervis, M. (1999). The effect of weather and climate on bicycle commuting. Transportation Research Part A: Policy and Practice, 33(6), 417-431. doi: http://dx.doi.org/10.1016/S09658564(98)00022-6

O'Connor, J., \& Brown, T. (2010). Riding with the sharks: serious leisure cyclist's perceptions of sharing the road with motorists. Journal of Science and Medicine in Sport, 13(1), 53-58.

Parkin, J., Wardman, M., \& Page, M. (2008). Estimation of the determinants of bicycle mode share for the journey to work using census data. Transportation, 35(1), 93-109.

Pinjari, A., Bhat, C., \& Hensher, D. (2009). Residential self-selection effects in an activity time-use behavior model. Transportation Research Part B: Methodological, 43(7), 729-748.

Pucher, J., \& Buehler, R. (2008). Making cycling irresistible: lessons from the Netherlands, Denmark and Germany. Transport Reviews, 28(4), 495-528.

Rietveld, P., \& Daniel, V. (2004). Determinants of bicycle use: do municipal policies matter? Transportation Research Part A: Policy and Practice, 38(7), 531-550.

Ryley, T. (2006). Use of non-motorised modes and life stage in Edinburgh. Journal of Transport Geography, 14(5), 367-375.

Sener, I. N., Eluru, N., \& Bhat, C. R. (2009). Who are bicyclists? Why and how much are they bicycling? Transportation Research Record: Journal of the Transportation Research Board, 2134(1), 63-72.

Statistics Canada. (2011). Canadian Census.

Stinson, M., \& Bhat, C. (2004). Frequency of Bicycle Commuting: Internet-Based Survey Analysis. Transportation Research Record(1878), 122-130. doi: 10.3141/1878-15

Tilahun, N., Levinson, D., \& Krizek, K. (2007). Trails, lanes, or traffic: Valuing bicycle facilities with an adaptive stated preference survey. Transportation Research Part A: Policy and Practice, 41(4), 287-301.

Titze, S., Stronegger, W., Janschitz, S., \& Oja, P. (2007). Environmental, social, and personal correlates of cycling for transportation in a student population. Journal of Physical Activity \& Health, 4(1).

Vélo Québec. (2010). L'état du vélo au Québec en 2010: zoom sur Montréal. In V. Québec (Ed.), L'état du vélo au Québec (pp. 28). Montréal: Vélo Québec. 
1

Vredin Johansson, M., Heldt, T., \& Johansson, P. (2006). The effects of attitudes and personality traits on mode choice. Transportation Research Part A: Policy and Practice, 40(6), 507-525.

Wardman, M., Tight, M., \& Page, M. (2007). Factors influencing the propensity to cycle to work. Transportation Research Part A: Policy and Practice, 41(4), 339-350.

Willis, D. P., Manaugh, K., \& El-Geneidy, A. Cycling Under Influence: Summarizing the influence of perceptions, attitudes, habits and social environments on cycling for transportation.

Xing, Y., Handy, S., \& Buehler, T. (2008). Factors associated with bicycle ownership and use: A study of 6 small US cities. Paper presented at the Annual Meeting of the Transportation Research Board, Washington, DC.

Xing, Y., Handy, S., \& Mokhtarian, P. (2010). Factors associated with proportions and miles of bicycling for transportation and recreation in six small US cities. Transportation Research Part $D$ : Transport and Environment, 15(2), 73-81. 